OPEN ACCESS

Edited by:

Tzu Pin Lu,

National Taiwan University, Taiwan

Reviewed by: Alessandro Rizzo,

Sant'Orsola-Malpighi Polyclinic, Italy Chi-Cheng Huang,

Taipei Veterans General Hospital,

Taiwan

Ying-Cheng Chiang,

National Taiwan University, Taiwan

${ }^{*}$ Correspondence: Hong Chen

qsdyyych@163.com Xinmin Li

xinminli@mednet.ucla.edu

${ }^{t}$ These authors have contributed equally to this work

Specialty section: This article was submitted to Cancer Genetics,

a section of the journal

Frontiers in Oncology

Received: 21 March 2021 Accepted: 17 May 2021

Published: 07 June 2021

Citation:

Wang $Y$, Tong Z, Zhang W, Zhang W, Buzdin A, Mu X, Yan Q,

Zhao X, Chang $\mathrm{H}-\mathrm{H}$, Duhon $\mathrm{M}$,

Zhou X, Zhao G, Chen H and LiX

(2021) FDA-Approved and

Emerging Next Generation Predictive Biomarkers for Immune Checkpoint Inhibitors in Cancer Patients.

Front. Oncol. 11:683419. doi: 10.3389/fonc.2021.683419

\section{FDA-Approved and Emerging Next Generation Predictive Biomarkers for Immune Checkpoint Inhibitors in Cancer Patients}

\author{
Ye Wang ${ }^{1 \dagger}$, Zhuang Tong ${ }^{2 \dagger}$, Wenhua Zhang ${ }^{1}$, Weizhen Zhang $^{3}$, Anton Buzdin ${ }^{4,5,6}$, \\ Xiaofeng Mu ${ }^{1,7}$, Qing Yan ${ }^{1}$, Xiaowen Zhao ${ }^{1}$, Hui-Hua Chang ${ }^{8}$, Mark Duhon ${ }^{8}$, Xin Zhou ${ }^{9}$, \\ Gexin Zhao ${ }^{8}$, Hong Chen ${ }^{9 *}$ and Xinmin $\mathrm{Li}^{8^{*}}$ \\ ${ }^{1}$ Clinical Laboratory, Qingdao Central Hospital, The Second Affiliated Hospital of Medical College of Qingdao University, \\ Qingdao, China, ${ }^{2}$ Liaoning Cancer Hospital and Institute, Cancer Hospital of China Medical University, Shenyang, China, \\ ${ }^{3}$ Department of Biology, University of California - Santa Cruz, Santa Cruz, CA, United States, ${ }^{4}$ Shemyakin-Ovchinnikov \\ Institute of Bioorganic Chemistry, Russian Academy of Sciences, Moscow, Russia, ${ }^{5}$ Department of Biological and Medical \\ Physics, Moscow Institute of Physics and Technology, Moscow, Russia, ${ }^{6}$ World-Class Research Center "Digital Biodesign \\ and Personalized Healthcare", Sechenov First Moscow State Medical University, Moscow, Russia, ${ }^{7}$ Academy of Medical \\ Engineering and Translational Medicine, Tianjin University, Tianjin, China, ${ }^{8}$ Department of Pathology \& Laboratory Medicine, \\ University of California, Los Angeles (UCLA) Technology Center for Genomics \& Bioinformatics, Los Angeles, CA, United \\ States, ${ }^{9}$ Department of Medicine, Qiqihaer First Hospital, Qiqihar, China
}

A patient's response to immune checkpoint inhibitors (ICls) is a complex quantitative trait, and determined by multiple intrinsic and extrinsic factors. Three currently FDA-approved predictive biomarkers (progra1mmed cell death ligand-1 (PD-L1); microsatellite instability (MSI); tumor mutational burden (TMB)) are routinely used for patient selection for $\mathrm{ICl}$ response in clinical practice. Although clinical utility of these biomarkers has been demonstrated in ample clinical trials, many variables involved in using these biomarkers have poised serious challenges in daily practice. Furthermore, the predicted responders by these three biomarkers only have a small percentage of overlap, suggesting that each biomarker captures different contributing factors to $\mathrm{ICl}$ response. Optimized use of currently FDA-approved biomarkers and development of a new generation of predictive biomarkers are urgently needed. In this review, we will first discuss three widely used FDAapproved predictive biomarkers and their optimal use. Secondly, we will review four novel gene signature biomarkers: T-cell inflamed gene expression profile (GEP), T-cell dysfunction and exclusion gene signature (TIDE), melanocytic plasticity signature (MPS) and B-cell focused gene signature. The GEP and TIDE have shown better predictive performance than PD-L1, and PD-L1 or TMB, respectively. The MPS is superior to PD-L1, $\mathrm{TMB}$, and TIDE. The B-cell focused gene signature represents a previously unexplored predictive biomarker to $\mathrm{ICl}$ response. Thirdly, we will highlight two combined predictive biomarkers: TMB+GEP and MPS+TIDE. These integrated biomarkers showed improved predictive outcomes compared to a single predictor. Finally, we will present a potential 
nucleic acid biomarker signature, allowing DNA and RNA biomarkers to be analyzed in one assay. This comprehensive signature could represent a future direction of developing robust predictive biomarkers, particularly for the cold tumors, for $\mathrm{ICl}$ response.

Keywords: immune checkpoint inhibitors, predictive biomarkers, PD-1, TMB, FDA-approved biomarkers

\section{INTRODUCTION}

Immunotherapy has changed the treatment landscape of many different cancer types in recent years. As opposed to chemotherapy and targeted therapy, which directly target tumor cells, immunotherapy stimulates a patient's immune response or enhances a patient's ability to fight against tumor cells. There are several different forms of immunotherapy used clinically, including cytokines, antibodies, vaccines, and immune checkpoint inhibitors (ICIs). Among those, ICIs are the most widely investigated and clinically used in the treatment of tumors.

ICIs target immune checkpoint regulators such as cytotoxic T-lymphocyte associated protein 4 (CTLA4), programmed cell death-1 (PD-1), or programmed death ligand 1 (PD-L1). Since the FDA approval of CTLA-4 inhibitor (ipilimumab) in 2011, the FDA has approved six more ICIs (1). Of those, three are PD-1 inhibitors (nivolumab, pembrolizumab and cemiplimab), and three are PD-L1 inhibitors (atezolizumab, avelumab, and durvalumab). These ICIs are widely utilized in around 15 tumor types (2) by oncologists in their daily practice and have shown remarkable efficacy.

However, ICI treatments are only effective in approximately $20 \%$ to $30 \%$ of cancer patients whose tumors are generally hot tumors with a high degree of $\mathrm{T}$ cell infiltration and high immune checkpoint expression (3). The majority of patients have no response or are resistant to the treatment, which is largely associated with cold tumors with few or absence of $\mathrm{T}$ cells, low tumor mutational burden, and poor antigen presentation (3). Furthermore, the efficacy varies among different tumor types, which further complicates treatment strategy. Given the expensive nature of immunotherapy, how to efficiently identify and select potential responders has become a clinical challenge to the effective use of ICIs. There is an urgent need to develop and validate more accurate biomarkers to assist in patient selection for ICI treatment.

Several different forms of predictive biomarkers have been developed for optimized use of immunotherapy, including positive predictive biomarkers to predict response to ICI, negative predictive biomarkers to predict resistance to ICI $(4,5)$, and side effect biomarkers to predict immune-related toxicity (6). Of those, the most validated and clinically used biomarkers for ICI responses are three FDA-approved positive predictive biomarkers: programmed death-ligand 1 (PD-L1), microsatellite instability/defective mismatch repair (MSI/dMMR), and tumor mutational burden (TMB). These three biomarkers have been reviewed extensively in the literature. For the most recent review, the readers can refer to Alessandro Rizzo et al.'s article in biliary tract cancer (7). Here, we do not intend to further review those biomarkers in general. Instead, we will focus on the challenges and solutions for effective use of these FDA-approved biomarkers.

The use of these three FDA-approved biomarkers has played a significant role in assisting appropriate selection of patients for ICI treatment. However, PD-L1, MSI/dMMR, and TMB each have different assays suitable to distinct tumor types and unique limitations. There is a lack of well-defined best practices to implement these biomarkers. In this article, we will review these three widely used biomarkers in clinical practice and discuss their strengths and weaknesses with the aim to standardize and optimize methodology. We will also review four promising gene signature biomarkers and two combinational gene signature biomarkers with an aim to explore more effective and accurate biomarkers suitable for larger tumor patient population, including immunologically cold tumors. These new forms of biomarkers are emerging and have shown impressive predictive power for ICIs. Finally, we will explore a comprehensive nucleic acid biomarker for future direction.

\section{THREE FDA APPROVED PREDICTIVE BIOMARKERS}

\section{PD-L1 \\ FDA Approval and Rationale}

PD-L1 was the first FDA-approved predictive biomarker for non-small-cell lung cancer (NSCLC) in 2015. Since then, the FDA has proved PD-L1 as a companion or complementary diagnostic test for six additional tumor types (gastric or gastroesophageal junction adenocarcinoma, cervical cancer, urothelial carcinoma, head and neck squamous cell carcinoma (HNSCC), esophageal squamous cell carcinoma (ESCC), and triple-negative breast carcinoma (TNBC)). Today, $\mathrm{PD}-\mathrm{L} 1$ is the most investigated and clinically used predictive biomarker for ICIs.

PD-1 and PD-L1 belong to the family of immune checkpoint proteins. Their interaction plays a key role in regulating the immune system to ensure that it is activated only at the appropriate time to minimize excessive inflammation and autoimmune reactions. PD-L1 is expressed on a variety of normal and immune cells such as dendritic cells, activated $\mathrm{T}$ and B lymphocytes, and macrophages. However, tumor cells have also adopted this PD-1/PD-L1 interaction mechanism through expressing PD-L1 on the tumor cell surface. Binding of tumor PD-L1 to PD-1 on T cells results in attenuation or inhibition of $\mathrm{T}$ cell activity, which helps tumor cells escape from immune surveillance (8).

Blocking the PD-L1 and PD-1 interaction enables the reactivation of $\mathrm{T}$ cells and enhancement of $\mathrm{T}$ cell activity to 
fight tumor cells. Since the number of tumor cells that express PD-L1 largely affects its ability to suppress immunogenicity and further determine the effectiveness of PD-L1 and PD-1 blockage by ICI, the expression of PD-L1 on tumor cells is a predictive biomarker for ICI therapy.

\section{Different Test Methods and Challenges}

Four FDA-approved IHC testing methods are available today for measuring PD-L1 expression (Table 1). These methods use different antibodies, different scoring systems, different PD-L1 expression thresholds, and different types of cells expressing PDL1. These variables among four methods are reflected in FDA approvals across seven different tumor types (Table 2).

These variabilities have posed practical challenges for clinicians and pathologists in daily practice. There is often confusion surrounding the different FDA-approved parameters in the tumor type and specific ICI administered. Consequently, although most widely used, PD-L1 has poor diagnostic accuracy overall, with a particularly low negative predictive value. For example, up to $20 \%$ of patients have PD-L1 negative tumors were reported to benefit from PD-1/PD-L1 antibodies (9). In addition to testing variables that contribute to low diagnostic accuracy, PD-L1 itself, as a predictive biomarker, has a relatively low predictability. Davis and Patel (2) analyzed 45 PD-L1 FDA approvals from 2011 to April 2019, and found that PD-L1 was only predictive in $28.9 \%$ of the approvals. Furthermore, PD-L1 expression is temporally and spatially regulated (10) and can be altered with prior therapeutic treatment (11). The combination of these factors limits PD-L1's predictability in certain circumstances.

\section{Future Directions}

Although PD-L1 testing has low diagnostic accuracy overall, it has value for certain tumor types and remains the most widely used predictive biomarker in current clinical practice. A recent systematic review and meta-analysis showed that PD-L1 can effectively predict survival benefit in the patients with metastatic urothelial carcinoma (12), and soluble forms of PD-L1 and PD-1 in plasma samples can also predict sunitinib efficacy in patients with metastatic clear cell renal cell carcinoma (13). To improve clinical utility of PD-L1, future efforts should be directed to the following three areas:

a) Making effort to standardize future assay in clinical trials. Current variability of four PD-L1 assays is largely attributed to the initial clinical trials that had evaluated different PD-1/ PD-L1 antibodies, used different scoring criteria and cut-offs for PD-L1, and stained different cell types. The organizations that design future clinical trials should consider possible standardization for the areas that can be potentially standardized in the planning stage.

b) Exploring standardization of currently-approved assays for clinical practice. For the currently-approved four commercial PD-L1 assays, we should explore possible standardization. A recent multi-center study compared the performance of 4 PD-L1 assays in lung cancer (14). They found that 22C3 for pembrolizumab, 28-8 for nivolumab, and SP263 for durvalumab are comparable to each other in the staining of tumor tissue. This result opens the possibility of using specific tests interchangeably. Among 11 FDA-approved PD-L1 linked companion diagnostic tests for seven tumor types (https://www.fda.gov/medical-devices/vitro-diagnostics/listcleared-or-approved-companion-diagnostic-devices-vitroand-imaging-tools), six tests for six tumor types used the PDL1 IHC 22C3 pharmDx assay, six tests for five tumor types used tumor cells and immune cells for PD-L1 staining, and five tests for five tumor types used Combined Positive Score (CPS) as the scoring system. CPS is the number of PD-L1 staining cells (tumor cells, lymphocytes, and macrophages) divided by the total number of viable tumor cells, multiplied by 100 . Therefore, the PD-L1 IHC 22C3 pharmDx assay, tumor cells, and immune cells for PD-L1 staining and the CPS scoring system could be considered as bases for future standardization.

TABLE 1 | Variables for FDA Approved PD-L1 Test.

\begin{tabular}{|c|c|}
\hline Testing Method & $\begin{array}{ll}\text { - } & \text { PD-L1 IHC 22C3 pharmaDx } \\
\text { - } & \text { PD-L1 IHC 28-8 pharmaDx assay } \\
\text { - } & \text { PD-L1 IHC SP } 142 \\
\text { - } & \text { PD-L1 IHC SP263 }\end{array}$ \\
\hline Scoring System & $\begin{array}{l}\text { - TPS - Tumor Proportion Score, which is the percentage of viable tumor cells showing partial or complete membrane staining at any } \\
\text { intensity } \\
\text { - CPS- Combined Positive Score, which is the number of PD-L1 staining cells (tumor cells, lymphocytes, macrophages) divided by the } \\
\text { total number of viable tumor cells, multiplied by } 100 \\
\text { - } \% \text { IC - The proportion of tumor area occupied by PD-L1 expressing tumor-infiltrating immune cells of any intensity }\end{array}$ \\
\hline PD-L1 Expression & - $\quad>=1 \%$ \\
\hline Threshold & $\begin{array}{ll}\cdot \vec{b} & >=5 \% \\
\cdot & >=10 \% \\
\cdot & >=50 \%\end{array}$ \\
\hline
\end{tabular}


TABLE 2 | Key Parameters for Use of FDA Approved PD-L1 Testing for Immune Checkpoint Inhibitors.

\begin{tabular}{|c|c|c|c|c|c|c|c|}
\hline Test Name & PMA\# & Tumor Type & $\mathrm{ICI}$ & $\begin{array}{l}\text { Approval } \\
\text { Year }\end{array}$ & $\begin{array}{l}\text { Scoring } \\
\text { System }\end{array}$ & PD-L1-Threshold & PD-L1 Staining \\
\hline $\begin{array}{l}\text { PD-L1 IHC 22C3 } \\
\text { pharmDx }\end{array}$ & P150013 & NSCLC & Pembrolizumab & 2015 & TPS & $>=50 \%$ & tumor cells \\
\hline $\begin{array}{l}\text { PD-L1 IHC 22C3 } \\
\text { pharmDx }\end{array}$ & $\begin{array}{l}\text { P150013/ } \\
\text { S006 }\end{array}$ & $\begin{array}{l}\text { gastric or GEJ } \\
\text { adenocarcinoma }\end{array}$ & Pembrolizumab & 2017 & CPS & $>=1$ & $\begin{array}{l}\text { tumor cells, } \\
\text { lymphocytes, } \\
\text { macrophages }\end{array}$ \\
\hline $\begin{array}{l}\text { PD-L1 IHC 22C3 } \\
\text { pharmDx }\end{array}$ & $\begin{array}{l}\text { P150013/ } \\
\text { S009 }\end{array}$ & Cervical Cancer & Pembrolizumab & 2018 & CPS & $>=1$ & $\begin{array}{l}\text { tumor cells, } \\
\text { lymphocytes, } \\
\text { macrophages }\end{array}$ \\
\hline $\begin{array}{l}\text { PD-L1 IHC 22C3 } \\
\text { pharmDx }\end{array}$ & $\begin{array}{l}\text { P150013/ } \\
\text { S011 }\end{array}$ & urothelial carcinoma & Pembrolizumab & 2018 & CPS & $>=10$ & $\begin{array}{l}\text { tumor cells, } \\
\text { lymphocytes, } \\
\text { macrophages }\end{array}$ \\
\hline $\begin{array}{l}\text { PD-L1 IHC 22C3 } \\
\text { pharmDx }\end{array}$ & $\begin{array}{l}\text { P150013/ } \\
\text { S014 }\end{array}$ & $\begin{array}{l}\text { head and neck } \\
\text { squamous cell } \\
\text { carcinoma }\end{array}$ & Pembrolizumab & 2019 & CPS & $>=1$ & $\begin{array}{l}\text { tumor cells, } \\
\text { lymphocytes, } \\
\text { macrophages }\end{array}$ \\
\hline $\begin{array}{l}\text { PD-L1 IHC 22C3 } \\
\text { pharmDx }\end{array}$ & $\begin{array}{l}\text { P150013/ } \\
\text { S016 }\end{array}$ & $\begin{array}{l}\text { esophageal squamous } \\
\text { cell carcinoma }\end{array}$ & Pembrolizumab & 2019 & CPS & $>=10$ & $\begin{array}{l}\text { tumor cells, } \\
\text { lymphocytes, } \\
\text { macrophages }\end{array}$ \\
\hline $\begin{array}{l}\text { VENTANA PD-L1 } \\
\text { (SP142) Assay }\end{array}$ & $\begin{array}{l}\mathrm{P} 160002 / \\
\text { S006 }\end{array}$ & $\begin{array}{l}\text { urothelial carcinoma/ } \\
\text { NSCLC }\end{array}$ & atezolizumab & 2018 & $\begin{array}{l}\mathrm{IC} \% / \mathrm{IC} \% \\
\text { or TPS }\end{array}$ & $>=5 \% />=10 \%$ or $>=50 \%$ & $\begin{array}{l}\text { tumor area/tumor } \\
\text { area, tumor ells }\end{array}$ \\
\hline $\begin{array}{l}\text { VENTANA PD-L1 } \\
\text { (SP142) Assay }\end{array}$ & $\begin{array}{l}\text { P160002/ } \\
\text { S009 }\end{array}$ & $\begin{array}{l}\text { Triple-Negative Breast } \\
\text { Carcinoma }\end{array}$ & atezolizumab & 2019 & $\mathrm{IC} \%$ & $>=1 \%$ & tumor area \\
\hline $\begin{array}{l}\text { VENTANA PD-L1 } \\
\text { (SP142) Assay }\end{array}$ & $\begin{array}{l}\text { P160002/ } \\
\text { S012 }\end{array}$ & NSCLC & atezolizumab & 2020 & IC\%/TPS & $>=10 \% />=50 \%$ & $\begin{array}{l}\text { tumor area } \\
\text { Tumor cells }\end{array}$ \\
\hline $\begin{array}{l}\text { PD-L1 IHC 28-8 } \\
\text { pharmDx }\end{array}$ & $\begin{array}{l}\text { P150025/ } \\
\text { S013 }\end{array}$ & NSCLC/SCCHN/UC & $\begin{array}{l}\text { Nivolumab in } \\
\text { combination with } \\
\text { ipilimumab }\end{array}$ & 2020 & TPS & $>=1 \%$ & tumor cells \\
\hline $\begin{array}{l}\text { PD-L1 IHC } \\
\text { SP263 }\end{array}$ & P160046 & urothelial carcinoma & Durvalumab & 2017 & $\begin{array}{l}\text { TPS/ICP/ } \\
\mathrm{IC}+\end{array}$ & $\begin{array}{c}>=25 \% / \mathrm{ICP}>1 \% \text { and } \mathrm{IC}+ \\
>=25 \% / \mathrm{ICP}=1 \% \text { and } \mathrm{IC}+= \\
100 \%\end{array}$ & $\begin{array}{l}\text { tumor cells } \\
\text { Immune cells }\end{array}$ \\
\hline
\end{tabular}

c) Standardizing routinely used PD-L1 test may face a practical challenge and will take time. Currently, the most reliable and effective approach is to follow FDA-approved parameters for PD-L1 assays in seven tumor types. Pathologists and oncologists should use specific ICIs, scoring systems, stained cells, thresholds, assay platforms, and tumor types according to the approved PD-L1 test, and must be cautious in using ICIs beyond the approved assays.

\section{MSI/dMMR}

\section{FDA Approval and Rationale}

MSI/dMMR was the second FDA-approved predictive biomarker for the pembrolizumab treatment of adult and pediatric patients with unresectable or metastatic solid tumors in 2017. The approval of pembrolizumab for MSI-H (MSI-high)/dMMR cancer treatment was based on the evidence of efficacy (ORR of 39.6\%, complete response rate of $7 \%$, and duration of response of six months or longer in $78 \%$ of responding patients) from five clinical trials (15). This approval represents the first drug that has been approved for solid tumors in general based on a common biomarker rather than for a specific tumor type (e.g. PD-L1).

Tumors with a defective DNA mismatch repair (dMMR) system accumulate thousands of mutations across the genome. Since short tandem repeats are particularly prone to mismatch errors, dMMR-induced hypermutations are most frequently located in microsatellite regions (1-6 nucleotides short stretches of DNA). This condition is defined as microsatellite instability (MSI). MSI results from and is a marker of dMMR.

Tumors with dMMR will also have more mutations in nonMSI regions throughout the genome and expectedly have more neoantigens compared to those with intact MMR. This assumption has been demonstrated by experimental data. Le et al. (16) reported that an average of 1782 mutations were present in colorectal cancers with dMMR compared with 73 mutations in the same tumors with intact MMR; consistently, 578 and 21 predicted neoantigens were found, respectively. The increased neoantigens in dMMR tumors are positively associated with overall lymphocytic infiltration, tumor-infiltrating lymphocytes, T helper 1 cells, and memory T cells $(17,18)$, which will render more effective antitumor immune response and a higher likelihood of response to immunotherapy. Thus, MSI/dMMR is a rational predictive biomarker for the treatment response to ICIs targeting PD-1, PD-L1, and CTLA-4 checkpoint receptor in such tumors.

\section{Different Test Methods and Challenges}

The FDA has approved pembrolizumab to be used in advanced MSI-H/dMMR solid tumors, but has not specified which assay should be used to measure MSI-H/dMMR. There are three different assays available for determining MSI-H/dMMR status in clinical practice: IHC for detecting dMMR, and PCR and NGS for detecting MSI-H (19-21).

IHC test for determining dMMR involves four proteins: MLH1, MSH2, MSH6, and PMS2. Loss of expression of one or 
more MMR proteins is considered as dMMR. MLH1 and MSH2 are obligatory proteins, and PMS2 and MSH6 are secondary proteins. PMS2 and MSH6 can form a heterodimer only with MLH1 and MSH2, respectively, while MLH1 and MHS2 can form heterodimers with other MMR proteins in addition to PMS2 and MSH6, respectively. The mutations in obligatory proteins result in functional loss of both obligatory and secondary binding partners, but the reverse is not true because secondary proteins can be substituted in the heterodimer by other MMR proteins. Consequently, antibodies against the secondary proteins detect mutations in both obligatory and secondary proteins, but antibodies for obligatory proteins alone do not detect mutations in PMS2 or MSH6 abnormalities. For this reason, some of the IHC assays only test PMS2 and MSH6.

IHC is a simple, cost-effective and widely available laboratory test that can be easily performed in all hospitals, clinics, and testing labs. The downside of IHC is a relatively low analytic sensitivity and accuracy due to technical or biological reasons. Technical reasons resulting in false negative staining can include pre-analytical issues, such as tissue fixation (22). Biologically, missense mutations in any MMR gene that can result in functional inactivation of a protein without affecting its antigenicity and expression levels (23).

PCR test is the second established method for determining MSI-H. Several PCR panels have been proposed, but two are most widely used in clinical practice: (i) a panel with two mononucleotide (BAT-25 and BAT-26) and three dinucleotide (D5S346, D2S123 and D17S250) repeats, which was proposed in 1997 by an international consensus group, also known as the Bethesda panel (24). Both tumor and paired normal tissue are required for using this panel; (ii) a panel with five poly-A mononucleotide repeats (BAT-25, BAT-26, NR-21, NR-24, NR-27). This five poly-A panel has a higher sensitivity and specificity compared to the Bethesda panel (25) and also does not need corresponding normal tissue for the test. If two of these five biomarkers in either panel lose stability, the tumor is diagnosed as having MSI-H. Recently, Thermo Fisher released a new TrueMark MSI Assay with a panel of 13 microsatellite biomarkers. In addition to expanded content from the five poly-A panel discussed above, this panel has a faster and simpler workflow, requires only 2ng FFPE tumor DNA and does not require the use of a tumor-normal match.

Since MSI testing by PCR is based on a specific and limited number of microsatellites analyses, the test cannot capture full MSI profiles and thus misses around $0.3 \%$ to $10 \%$ of cases (26). Furthermore, although MSI can be present in almost all solid tumor types, its prevalence and type of MSI are widely variable across the different tumor types. Several major cancer types, like NSCLC, breast cancer and prostate cancer have only 1-2\% prevalence while other cancer types, such as melanoma and kidney cancer, have no data available $(27,28)$. The majority of clinical data for predictive ability for ICIs were largely from CRC. These factors limit its use as an effective and reliable predictive biomarker for ICIs in a broad scale, despite being approved for all solid tumors.

NGS-based MSI-H/dMMR testing is a relatively new assay and can overcome the limitations of MSI testing by PCR to a certain degree. NGS test uses either cancer gene panels or whole exome sequencing. For cancer gene panels, the number of genes varies from focused cancer gene panes with around 500 genes to comprehensive cancer exomes with $>5000$ genes (29). A bioinformatics method, MSIsensor, has also been developed to predict MSI status using whole exome data (30). The MSIsensor prediction showed $100 \%$ agreement with gold standard methods of IHC and PCR for MSI testing in 130 CRC patients.

The main advantage of NGS is its ability to evaluate a large number and different types of microsatellites including two- to six-base repeats, and to discover additional microsatellites with better predictive power. As opposed to PD-L1 and MSI testing, which are primarily suitable for metastatic colorectal cancer and other cancers belonging to the spectrum of Lynch syndrome, NGS method can be used for all tumor types, including nonLynch syndrome rare cancers for multiple ICIs. Because NGS is the primary method to evaluate TMB, which will be discussed later, another advantage of NGS-based MSI-H/dMMR testing is the ability to integrate MSI with TMB data for the prediction of ICIs. The main challenges of NGS testing are its high cost, technical demands and lack of wide availability. Once these hurdles are overcome, NGS-based MSI testing will be a more accurate and sensitive assay than PCR or IHC for determining MSI status (21).

\section{Future Directions}

IHC-dMMR, PCR-MSI-H, and NGS-MSI-H each have strengths and weaknesses (Table 3). Although agreement has been found among the three methods, especially in CRC, differences exist across cancer types. The FDA has granted approval for the use of Pembrolizumab, nivolumab, and nivolumab-ipilimumab combination in metastatic solid cancers with MSI-H or dMMR, but did not specify which assay should be used to measure MSI status. A clear guideline is needed to help pathologists make informed decisions about which method to use in a given clinical situation. The CAP and three collaborating societies are developing a clinical guideline for testing MSI in patients with a range of cancer types. The groups opened the public comment period for the guideline in February, which ended on March 13, 2020. Formal guidelines are expected to be released soon. The European Society for Medical Oncology (ESMO) has already published its recommendations as of 2020 (28). Taken together, three general considerations can improve effective utilization of these assays:

a) The first and most important consideration is the prevalence of MSI in different tumor types. Although MSI-H can be present in almost all solid tumor types, its prevalence is widely variable across the different tumor types. MSI testing should be performed using IHC, PCR, or NGS method for the tumor types with high frequency of MSI, generally belonging to the spectrum of Lynch syndrome, including colorectal cancer (31), endometrial cancer (32), gastric cancer (33), ovarian cancer (34), and small Intestinal cancer (35). For other tumor types that do not belong to the spectrum of Lynch syndrome with low prevalence of MSI or no MSI data available on the 
TABLE 3 | Strengths, weaknesses and recommendations for three predictive MSI-H/dMMR biomarkers for ICl response.

\begin{tabular}{|c|c|c|c|}
\hline Assays & Strengths & Weaknesses & Recommendations \\
\hline IHC for & - Simple & - Too many variables & - $\quad$ First choice in general \\
\hline dMMR & $\begin{array}{ll}\text { - } & \text { Fast } \\
\text { - } & \text { Cost-effective } \\
\text { - } & \text { Widely available }\end{array}$ & $\begin{array}{l}\text { - } \quad \text { Hard to determine cut-off } \\
\text { Relatively low analytic sensitivity } \\
\text { and accuracy }\end{array}$ & $\begin{array}{l}\text { - Use of all four antibodies } \\
\text { - Use for colorectal cancer and other spectrum of Lynch } \\
\text { syndrome when suitable }\end{array}$ \\
\hline PCR for & - Widely available & - $\quad$ Capture partial MSI profiles & - Use of five poly-A panel \\
\hline MSI-H & $\begin{array}{l}\text { - } \quad \text { Ease of use } \\
\text { Accurate for colorectal cancer and other } \\
\text { spectrum of Lynch syndrome }\end{array}$ & $\begin{array}{l}\text { - Low prevalence in some tumor } \\
\text { types }\end{array}$ & - Use after neoadjuvant therapy or in advanced tumors \\
\hline NGS for & - $\quad$ Capture full MSI profile & - High cost & - The last choice \\
\hline MSI-H & $\begin{array}{l}\text { - } \quad \text { Suitable for all tumor type } \\
\text { - } \quad \text { More accurate and sensitive } \\
\text { - Simultaneous detection of other potential } \\
\text { predictors }\end{array}$ & $\begin{array}{l}\text { - } \quad \text { Technical demands } \\
\text { - } \quad \text { Lack of wide availability } \\
\text { - } \quad \text { Need tumor-type specific cut- } \\
\text { off }\end{array}$ & $\begin{array}{l}\text { - } \quad \text { >300 genes in the panel } \\
\text { - } \quad \text { Standardize technical parameters wherever possible }\end{array}$ \\
\hline
\end{tabular}

reliability of IHC and the PCR method, such as NSCLC, breast cancer, melanoma, and kidney cancer, NGS-MSI should be considered because the NGS method can scan all types of MSI and also couple analyses of MSI with TMB.

b) The second consideration is the order of testing methods. In consideration of availability, cost and ease of testing, ESMO recommends IHC-dMMR as the first choice, and then PCRMSI when IHC results are indeterminate. However, previous studies showed that the expression of MMR proteins, commonly MSH6, can change after neoadjuvant therapy $(36,37)$ and that dMMR tumors are more common in early-stage disease of different cancer types (defined as stage $<\mathrm{IV}$ ) compared to advanced and metastatic settings (38). Given these two variables, the PCR-MSI should be a preferred testing method over IHC after neoadjuvant therapy or in advanced tumors. The last choice is NGS-MSI. The primary reason for recommending NGS-MSI last is due to the assay complexity, high cost and lower accessibility. Another complication of the NGS method is the determination of the appropriate threshold for calling MSI-H. Different NGS panels with different numbers of genes and different tumor types with different MSI frequency each impact threshold determination. It is practically difficult to reach a consensus threshold, which needs to be determined empirically and validated clinically for a specific NGS panel.

c) The third consideration is panel selection. For IHC-dMMR, antibodies for four MMR proteins (MLH1, MSH2, PMS2 and MSH6) should be used instead of MSH6 and PMS2 only. The mutations in MLH1 and MSH2 lead to loss of MLH1 and PMS2, and MSH2 and MSH6, respectively. However, there are isolated losses of PMS2, MSH2, or MSH6, which supports the notion of using all four antibodies to improve testing certainty and accuracy. For PCR-MSI, a panel with five polyA mononucleotide repeats (BAT-25, BAT-26, NR-21, NR-24, NR-27) is recommended over a panel with two mononucleotides (BAT-25 and BAT-26) and three dinucleotides (D5S346, D2S123 and D17S250) for higher sensitivity and specificity. For NGS-MSI, the number of genes in the panel should be at least $>300$. A panel of 20005000 genes may be a good compromise between cost and coverage.

\section{TMB}

\section{FDA Approval and Rationale}

TMB is a measure of the number of gene mutations in cancer cells and can be reported as the total number of nonsynonymous somatic mutations in the tumor exome (39) or per megabase DNA (40). TMB was recently approved for pembrolizumab for the treatment of adult and pediatric patients with unresectable or metastatic solid tumors in June 2020. Foundation One CDx assay (Foundation Medicine, Inc.) was also approved as a companion diagnostic test.

Several key factors can contribute to elevated TMB, including cigarette smoke, ultraviolet radiation, and defective damage response (DDR) genes (40). Among those factors, mutations in the DNA damage response (DDR) genes are particularly important, and emerging as independent predictors for ICI response. Teo et al. (41) observed that mutations in DDR genes are significantly associated with clinical benefit in patients receiving immunotherapy. Similar results were also reported in colorectal cancer (42), urothelial cancer (43), and serval other cancers (44). For a most recent review in this topic, please reference Minlin Jiang et al. (45). A high number of mutations in somatic exonic regions will lead to an increase in neoantigen production, some of which are immunogenic, and could then be recognized by $\mathrm{T}$ cells, resulting in improved antitumor immune responses. Consequently, patients with high TMB likely produce more intensified immune responses and are more sensitive to ICI treatments.

\section{Different Test Methods and Challenges}

There are 2 primary methods for evaluating TMB: WES and NGS panels. WES-TMB was first demonstrated to have an association with ICI response and proposed as a predictive marker for ICI by Snyder et al. (46) and Rizvi et al. (47), followed by many others $(48,49)$. These early WES-TMB studies count only nonsynonymous somatic mutations. TMB$\mathrm{H}$ (TMB high) was called using different cutoffs varying from $\geq 7.4$ in Esophagogastric cancer and $\geq 23.1$ in NSCLC when the number of nonsynonymous somatic mutations was reported as per megabase DNA, and from $\geq 158$ mutations in Advanced NSCLC to $\geq 248$ mutations in advanced SCLC when whole tumor exome bases were counted. These different reporting formats and 
cutoff values complicate clinical practice. In addition, the clinical utility of WES-TMB was limited by high cost, long turn-around time, technical complication, and availability (40).

To address the WES-TMB limitations, researchers developed NGS panels with a sufficiently large number of cancer-targeted genes to predict TMB $(50,51)$. Early pioneer studies demonstrated that properly designed and sufficiently large NGS panels can accurately recapitulate WES-TMB and be effectively used as an independent predictor of ICI treatment. Further analyses provided additional evidence on reproducibility, repeatability, and the limit of detection compared with WES, and demonstrated good agreement between NGS panels-derived and WES-derived TMB data (52, 53). Importantly, these targeted NGS panels with fewer DNA bases and relatively simpler assays have improved utility in clinical settings.

The calculation of TMB has different methods, depending on the assay adopted. The WES-TMB assays typically consider nonsynonymous somatic mutations in the analysis, while NGS panels have generally taken a more comprehensive approach, such as FundationOne $\mathrm{CDx}$, which includes synonymous and non-synonymous single-nucleotide variants (SNVs) for improved assay sensitivity (54), and insertions and deletions (indels) per area of coding genome sampled, but excludes known and likely oncogenic driver events and germline SNPs. There is currently no standard of TMB calculation. The TMB Harmonization Project is aimed to standardize TMB calculation and reporting (55-57).

There are two NGS panels commercially available that have been approved by regulatory bodies: (i) MSK-IMPACT with 468 cancer genes was cleared by the $510 \mathrm{~K}$ pathway for mutation profiling in November 2017, and (ii) the FoundationOne CDx assay with 324 cancer genes was approved by the FDA as a companion diagnosis for the evaluation of TMB in 2020. These targeted gene panels can analyze and identify single nucleotide substitutions, indels, CNAs, and selected gene rearrangements, as well as genomic signatures including microsatellite instability (MSI) and loss of heterozygosity in a single assay.

Overall, TMB as a predictive marker for ICI treatment is more technically challenging than PD-1 and MSI. Many variable factors can impact TMB estimation and output, including tumor type (different tumor types biologically have different TMB (39)), tissue type (FFPE tissue will artificially have more mutations than fresh frozen tissue), sequencing parameters (NGS panel content, size and sequencing depth, bioinformatics pipeline), and the reporting cutoff (55). The wide variation in TMB estimation and reporting methods across studies have limited effective adoption of TMB and stressed the need to standardize assays for determining TMB.

\section{Future Directions}

TMB-H is generally predictive of response to multiple forms of ICIs, but the predictive ability can vary across tumor types and mutation types. Since the affinity of neoantigen binding to MHC1 and T cell receptor recognition of neoantigen as foreign are two determinants of immune response, distinct qualities of neoantigens contribute to ICI response differently. Generally, the lack of similarity of neoantigen to self-antigens results in an increased ability to activate T-cells, and thus, predicts response to ICIs. For example, Merkel cell carcinoma (MCC), renal cell cancers (RCC), and mesothelioma all have higher response rates to ICIs than would be anticipated from their TMBs (58) due to the higher quality of antigens in these tumor types. Elevated antigen quality results from viral antigens (in MCC), a high number of indel mutations (in RCC), and complex chromosomal rearrangements (in mesothelioma) (59). Keeping these in mind, the below 3 points should be considered in TMB estimation and reporting:

a) A clinically validated, sufficiently large NGS panel is preferred over WES. In consideration of clinical utility (low cost, shorter turn-around time, use of smaller biopsy samples, higher assay sensitivity, lower technical complexity and bioinformatics demand), a standardized, commercially available NGS panel, such as FDA-approved FoundationOne $\mathrm{CDx}$, is recommended for TMB determination. When FoundationOne CDx panel is used, ones should follow approved method for TMB calculation (Douglas B et al., 2016). The panel should be sufficiently large, including $\geq 300$ targeted genes. These genes should be carefully selected by including the following: (i) other TMB-related marker genes, such as POLE whose mutations are associated with TMB-H in multiple solid tumor types like endometrial, CRC, gastric, melanoma, lung, and pediatric cancers (60-62), or BRAF and MET whose alterations are associated with longer duration of ICI treatment; (ii) other immunotherapy response-related genes, such as genes for MSI estimate, immune resistant gene, IDO1, and JAK $(4,5)$; (iii) multiple types of alterations, such as mutations, indels, amplifications, CNAs, and structure variations. Such a panel will be small enough for broader clinical application, but informative enough to allow performing multiomic analyses to provide a more comprehensive, complete, and robust patient biomarker profile for independent or joint ICI treatment decisions.

b) Weighted calculation for TMB score. Since different types of alterations have variable immunogenicity, one should not only focus on the number of mutations, but also consider the types of mutations when evaluating TMB. Generally, patients with frameshift indels, transversions, and clonal mutations are more immunogenic than those with nonsynonymous mutations (63), transitions (47), and branching or subclonal mutations (64), respectively. In calculating TMB status, the index may be expressed as a TMB score. The more immunogenic types of mutations should be preferably weighted. By using a TMB score, other factors that also affect TMB predictive value can also be considered, such as age (65).

c) Tumor-type specific reporting cutoffs. TMB estimation and reporting methods are widely variable in scientific publications. Like PD-L1, there is an urgent need to standardize current TMB assessment methods, which is essential for reliable use of TMB as a clinical biomarker for 
ICI response. However, among these variables, some technically related variations can be addressed by standardization, such as sequencing depth and gene panel, while others related to biological variations can be addressed according to biology. The variation in reporting cutoff is a typical example of biological variation. Some tumor types have naturally higher TMB than others (66), and thus require a different cutoff for reliable and reproducible ICI response prediction. For example, $>16$ mutations/Mb is appropriate for atezolizumab in urothelial carcinoma (67), while $>23.1$ mutations/Mb is needed for pembrolizumab in NSCLC (68). In fact, the TMB cutoff varied markedly across the top $20 \%$ of each cancer type (66), suggesting that it is unlikely to be able to use a universal cutoff. The optimal cutoff should be developed and validated in different tumor types.

\section{NON-FDA APPROVED EMERGING BIOMARKERS}

\section{Promising Mutation Predictive Biomarkers Inactivation of PTEN}

PTEN is ubiquitously expressed protein phosphatase that is one of the major human tumor suppressors (69). For example, it dephosphorylates PIP3 to PIP2 and thus inhibits PI3K/mTOR/ Akt signaling axis (70) and serves as the potent regulator of DNA repair (71). Even a single-allele mutation of PTEN can irreversibly repress molecular functions of this gene, thus making a cell susceptible to carcinogenesis (72). Decreased expression of PTEN is also connected with the sensitivity to ICIs which can be mediated by lower infiltration of such cells by T-lymphocytes (73). In lung cancer, mutations of PTEN were shown to be associated with poor response to ICI therapy (74).

\section{Mutations of POLE}

POLE is a subunit of DNA polymerase epsilon that has polymerase and proofreading activities, and participates in both DNA replication and repair (75). Mutations in proofreading domain of POLE are present in $1-12 \%$ of all tumors $(76,77)$ and result in approximately two orders greater mutation rate, thus directly influencing TMB (78). Tumors with POLE mutation have more neoantigens and more infiltrating lymphocytes (79).

\section{Linked Mutations of KRAS and STK11}

Somatic activating mutations in 12 and 13 codons of KRAS can be detected in 5-35\% of the patients in different cancer types (80) and most frequently are associated with poor survival prognosis (81). These mutations are statistically significantly linked with the mutations in the STK11 gene (82) that encodes LKB1 kinase which phosphorylates and activates AMPK, a potent metabolic regulator (83) that controls mTOR signaling (84). In lung cancer, up to $30 \%$ of tumors may have mutated STK11 (85), and presence of both STK11 and KRAS mutations is a factor of poor survival prognosis (86). Inactivation of STK11 is also a factor of more inert tumor microenvironment and lower expression of PD-L1 (87).
In lung cancer patients with mutant $K R A S$, ICI therapy showed lack of benefit, in contrast to the wild-type group of tumors (88). In KRAS mutant tumors, less patients responded on ICI therapy in a STK11-mutated subgroup compared to a TP53mutated subgroup ( $7.4 \%$ versus $35.7 \%$, respectively). The same was observed in clinical trials CheckMate057 (0\% vs. $57,1 \%)$, CheckMate-012 (0\% vs. 78\%) (89), and GEMINI (0\% vs. 53\%) (87). This also reflected statistically lower time to progression (TTP) in patients having both mutations in KRAS and STK11 genes compared to the tumor with only KRAS mutations (90).

In agreement with that, KRAS/STK11 double mutant lung cancers showed worse survival compared to only STK11 mutants: TTP of two months vs. five months, and overall survival of $\sim$ seven months vs 16 months (91). Bad prognosis of double mutant tumors was relatively independent on PD-L1 expression and was also true for the PD-L1-positive group of double mutants (90). Interestingly, these mutations can likely synergistically promote tumor infiltration by $\mathrm{T}$ cell suppressing neutrophils (92).

\section{Gene Signature Predictive Biomarkers}

Three FDA-approved predictive biomarkers, PD-L1, MSI/ $\mathrm{dMMR}$, and TMB have played a critical role in guiding ICI treatment selection. However, each has its limitations. PD-L1 has limited positive and negative predictive values, MSI-H/dMMR has a low prevalence in many common metastatic cancers $(<5 \%)$, and TMB is hindered by high cost and technical complications. Additionally, a wide range of response rates have been reported, such as patients with low TMB, absence of MSI or without PD-1/ PD-L1 expression showing good response, or vice versa. This unpredictability clearly indicates that immunotherapy response is also driven by other biomarkers. The identification and validation of additional predictive biomarkers are needed. Recently, gene expression-based signatures have emerged as a new generation of predictive biomarkers for ICI response. Here, we will discuss four different gene signature biomarkers: T cellinflamed gene expression profile (GEP), T cell dysfunction and exclusion gene signature (TIDE), melanocytic plasticity signature (MPS), and B cell-focused gene signature.

a) T cell-inflamed gene expression profile (GEP) is one of the early reported and clinically validated gene signatures for predicting response to pembrolizumab across multiple solid tumors (93). Through stepwise validation of several populations, an 18-gene pan-tumor signature was identified in 220 patients of nine different tumor types. This signature is represented by the genes related to IFN- $\gamma$ signaling, cytotoxic effector molecules, antigen presentation, and $\mathrm{T}$ cell active cytokines, which is a common characteristic of a $\mathrm{T}$ cellinflamed tumor microenvironment responsive to ICIs. Across multiple tumor types, data showed that responders have high level of signature gene expression (a T cell inflamed phenotype) while non-responders have low expression level across the signature genes (a non-T cell-inflamed phenotype). Its predictive value was demonstrated independently in a 96patient population with head and neck squamous cell carcinoma. ROC analysis showed that the 10-gene signature 
has a larger area under the ROC curve than that of PD-L1, demonstrating that the $\mathrm{T}$ cell-inflamed multigene signature has a better predictive value compared to the commonly used single gene biomarker, PD-L1.

b) The second promising gene expression panel is the $\mathrm{T}$ cell dysfunction and exclusion gene signature, termed TIDE for Tumor Immune Dysfunction and Exclusion. Different from $\mathrm{T}$ cell-inflamed gene signature, which captures a favorable tumor environment for ICI response (a high level of gene expression in the panel is indicative of response), TIDE focuses on the loss of $\mathrm{T}$ cell functionality, which reflects an unfavorable tumor environment for ICI response (a high level of gene expression in the panel is indicative of non-response). TIDE was developed based on two key mechanisms of tumor immune evasion $(94,95)$ : dysfunctional infiltrated $\mathrm{T}$ cells in the tumor, and prevention of $\mathrm{T}$ cell infiltration into the tumor. Using large data sets and computational modeling method, Peng Jiang et al. (96) identified gene signatures that underlie these two mechanisms of tumor immune escape separately and integratively.

Using publicly available transcriptome profiles of non-treated tumors with patient survival outcomes, the authors first used Cox proportional hazard (Cox- $\mathrm{PH}$ ) model to test the interaction of the expression of each gene in tumors with the level of $\mathrm{T}$ cell infiltration (defined as average gene expression of known regulators of $\mathrm{T}$ cell dysfunction) to influence patient survival. This systematic, statistical interaction test identified signature genes that affect $\mathrm{T}$ cell function and patient survival. The profiles of these genes are enriched by inflammatory and interferon response-related pathways and lack of pathways that promote $\mathrm{T}$ cell activation, reflective of $\mathrm{T}$ cell dysfunctional phenotype. Similarly, the authors used the expression profiles of three cell lines, MDSCs, TAMs, and CAFs that restrict T cell infiltration in tumors, to model $\mathrm{T}$ cell exclusion, and developed a gene signature of $\mathrm{T}$ cell exclusion. Finally, TIDE, an integrated signature, was developed to predict ICI response. ROC analysis showed that TIDE has better predictive performance than TMB and PD-L1 for both anti-PD1 and anti-CTLA4 therapies. In addition, a lower TIDE score is predictive of longer patient overall survival.

c) Melanocytic plasticity signature (MPS) was developed by studying four mouse immunocompetent melanoma models (M1-M4), which represent major subtypes of human cutaneous melanoma, and the diversity of clinical responses to ICIs. M1 and M2 mice had no response to anti-PD-L1 and sustained tumor growth, M3 mice had modest response and delayed tumor growth, and M4 had the best response and significantly longer survival time. By comparing RNAseq data of ICI-resistant M1 and M2 and the sensitive M3 and M4, and subsequent evaluation of response prediction in the Van Allen dataset, Eva Pérez-Guijarro et al. (97) identified a 45-gene signature predictive to ICI response. Low MPS scores were significantly associated with responders. In the Van Allen dataset, $81 \%$ of responsive patients can be correctly predicted by using MPS score. Furthermore, the patients with low MPS had longer progression-free survival and overall survival.

Further analyses showed that the 45-gene signature reflects the multipotency and differentiation of the melanocytic lineage. A high MPS score represents undifferentiation and multipotency, and a low MPS score indicates later stages of melanocytic differentiation. These data suggest multipotency and differentiation status of melanoma can predict ICI response, which represents a novel discovery. In a comparison of predictive performance among MPS, TIDE, TMB, and PD-L1, ROC analysis showed that MPS had the best ROC area under the curve (AUC) value followed by TIDE in the Van Allen and Hugo-Riaz data sets (97).

d) The B cell gene signature is a recently reported new biomarker for ICI response. Since current ICI treatments reinvigorate T cells against tumors, research of predictive biomarkers to ICI response in the past was largely focused on $\mathrm{T}$ cells. Several recent studies showed that the $\mathrm{B}$ cell rich immune cell population in tertiary lymphoid structures (TLS) of tumors is a critical discriminative feature of ICI responsiveness and patient overall survival (97-99). TLS are aggregates of immune cells and have been associated with increased patient survival in several cancer types. These recent studies further demonstrated that significantly enriched B cells localized in TLS, specifically switched memory B cells (99), are key predictors of ICI response. Helmink et al. also showed the presence of high diversity of B cell receptors in responders compared with non-responders. All these data demonstrated an active role of B cells and tertiary lymphoid structures in ICI response, and highlighted a possibility to develop predictive gene signatures for ICI response focused on $\mathrm{B}$ cells within TLS.

Cabrita et al. (98) constructed a TLS gene signature in metastatic melanoma. This signature is dominated by B cellspecific genes and is predictive of ICI response as well as patient overall survival. Cox regression analysis using several immune signatures across the four cohorts demonstrated that the TLS signature has the best predictive performance in the cohorts treated with anti-PD1. The predictive performance of TLS signature is independent of TMB. A similar B cell dominated gene signature was also developed in soft tissue sarcoma (100). Using the microenvironment cell populations (MCP-counter) method (101), the authors classified 608 tumors from different subtypes of soft-tissue sarcoma into five groups (A, B, C, D, and E) based on the composition of the tumor microenvironment. An immune-high group $\mathrm{E}$ was characterized by the high density of $\mathrm{B}$ cells and TLS. The key determinant of group $\mathrm{E}$ was the high expression of the B cell signature. Once again, the B cell signature was significantly associated with better ICI response and improved overall survival.

Of the above 4 gene signatures, the T cell-inflamed, GEP, and TIDE have superior predictive performance for ICI response compared to PD-L1, and PD-L1 or TMB, respectively. MPS has better predictive performance than PD-L1, TMB, and TIDE. The $\mathrm{B}$ cell focused gene signature is a new predictive biomarker, and 
its predictive value has yet to be thoroughly evaluated in relation to other established biomarkers. Based on currently available data, the gene expression-based signatures are generally more robust with enhanced predictive value compared to single gene or protein markers.

In addition, a proof of concept has been recently reported that next-generation expression signatures based on molecular pathway activation profiles $(102,103)$ using RNA sequencing data (104) can guide personalized ICI prescription in treatment refractory tumors (105).

\section{Combinational Predictive Biomarkers}

Currently FDA-approved and recently developed gene signature biomarkers for ICI response fall into two broad categories: one category is related to tumor intrinsic factors, such as TMB, MSI and MPS, and the other category is related to tumor extrinsic factors, including PD-L1, T cell, and B cell gene signatures (Figure 1). These biomarkers have independent predictive values for ICI response, but predicted responders across those biomarkers have a generally low percentage of overlapping, particularly between these two categories. This lack of correlation, together with the demonstrated individual predictive values, indicates that these biomarkers measure different aspects of complex tumor immunobiology and capture unique features of ICI response phenotypes. This suggests that the combination of different biomarkers may provide complementary or additive effects and lead to an improved predictive performance. Here, we will review two combined predictive biomarkers, GEP+TMB and MPS+TIDE, to demonstrate their improved predictive performance.

1) GEP+TMB. T cell-inflamed GEP and TMB measure $T$ cell activation (tumor microenvironment) and tumor antigenicity, respectively, representing unique aspects of tumor immunobiology. To understand the interplay between these two distinct categories of biomarkers, Cristescu et al. (106) explored the joint predictive response to pembrolizumab across 22 tumor types from four KEYNOTE clinical trials. The individual biomarker prediction was first performed, followed by classification of patients into four individual biomarker-defined response groups $\left(\mathrm{GEP}^{\mathrm{lo}} \mathrm{TMB}^{\mathrm{lo}}, \mathrm{GEP}^{\mathrm{lo}} \mathrm{TMB}^{\mathrm{hi}}, \mathrm{GEP}^{\mathrm{hi}} \mathrm{TMB}^{\mathrm{lo}}\right.$, and $\mathrm{GEP}^{\mathrm{hi}} \mathrm{TMB}^{\mathrm{hi}}$ ) using predefined cutoffs for TMB and GEP. The highest response rate was observed among patients in the group of $\mathrm{GEP}^{\mathrm{hi}} \mathrm{TMB}^{\text {hi }}$ in all four cohorts. No response was seen in the group of $\mathrm{GEP}^{\mathrm{lo}} \mathrm{TMB}^{\mathrm{lo}}$ in the pantumor and HNSCC cohorts, and intermediate response rate was observed in the group of either $\mathrm{TMB}^{\mathrm{lo}} \mathrm{GEP}^{\text {hi }}$ or $\mathrm{TMB}^{\text {hi }} \mathrm{GEP}^{\text {lo }}$. These data demonstrated that the combination of two biomarkers offers higher sensitivity and greater predictive value compared to a single biomarker. Additionally, the patients in the $\mathrm{GEP}^{\mathrm{hi}} \mathrm{TMB}^{\mathrm{hi}}$ group had longer progression-free survival time.

The joint utility of the GEP+TMB in predicting ICI response was further tested in TCGA database using 6384 patients of matched transcriptome and WES data across a wide range of tumor types. Consistent with the data derived from KEYNOTE clinical trials, the patients with $\mathrm{GEP}^{\mathrm{hi}} \mathrm{TMB}^{\text {hi }}$ had the strongest response, and $\mathrm{GEP}^{\mathrm{lo}} \mathrm{TMB}^{\text {lo }}$ group had no or poorest response to pembrolizumab, demonstrating that the improved response rate by joint prediction of GEP+TMB can be generalized across cancer types.

2) MSP+TIDE. As discussed above, MSP reflects cancer cell intrinsic factor (multipotency and differentiation), which is not associated with immune response, while TIDE represents extrinsic factor (immune phenotype) reflective of the tumor

\section{Biomarkers predictive of $\mathrm{ICI}$ response}

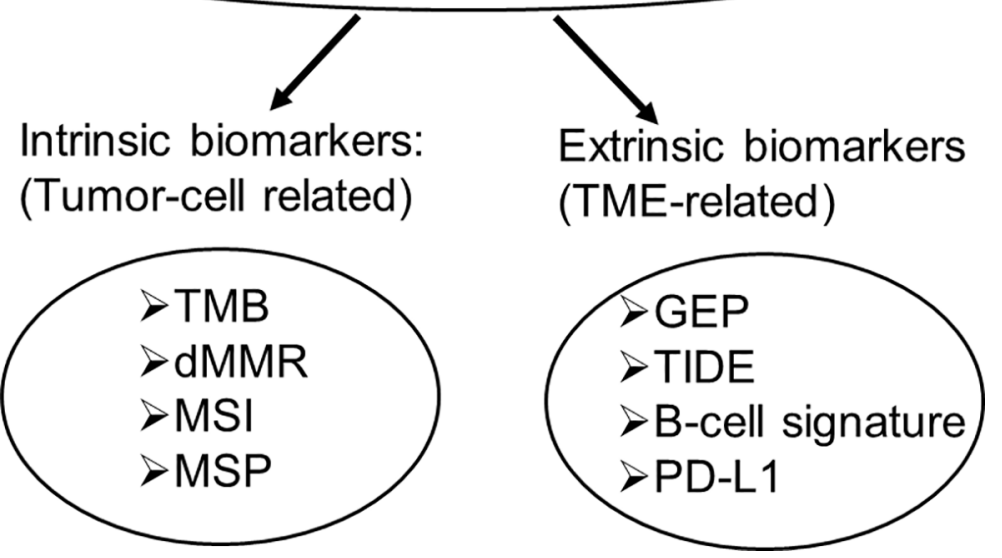

FIGURE 1 | Intrinsic and extrinsic biomarkers predictive of ICl response. Intrinsic biomarkers are tumor cell-related, extrinsic biomarkers are tumor microenvironment-related. 
microenvironment. Given these different features, Guijarro et al. (97) hypothesized that the combination of MPS and TIDE scores will increase predictive value. Indeed, ROC analysis showed a noticeable improvement of the AUC values by MPS+TIDE compared to any of the single methods in the Van Allen cohort.

The improved ICI response by combining MPS and TIDE signatures translated into patient survival. Similar to the GEP+TMB analysis described above, melanoma patients were classified into three groups based on their MPS and TIDE scores. The low-MPS and low-TIDE group showed significantly longer PFS and OS, whereas the high-MPS and high-TIDE group exhibited the poorest survival in Kaplan-Meier analysis.

Altogether, the results demonstrated that combining cancer cell intrinsic and extrinsic factor-related gene signatures can improve the predictability of not only ICI response, but also patient survival. This integrated predictive biomarker may represent a future direction for additional biomarker discovery.

\section{FUTURE DIRECTION OF PREDICTIVE BIOMARKER DISCOVERY}

The above analyses cover different predictive biomarkers from single to complex, DNA to RNA, and neoantigenic to TMErelated. All data suggest that patient response to ICIs is a complex quantitative trait determined by multiple factors (Figure 2). Current biomarkers tend to capture a unique contributing factor of ICI response. Thus, a combination of biomarkers should offer improved predictive performance to ICI response. Because of ICI-related toxicities and the high cost of these agents, current predictive biomarkers with a highly variable response to ICIs cannot fully meet clinical need. There is an urgent need to develop a new generation of biomarkers that can reliably predict ICI response. Based on current knowledge and available data, an optimal ICI predictive biomarker is an integrated nucleic acid biomarker signature. This signature can combine information from different DNA and RNA biomarkers in one single assay to retrieve as many ICI response-related contributors as possible, from the upstream to downstream of immune response, from intrinsic to extrinsic factors, and from TME to neoantigenic aspects. A final combined index score will be used to predict ICI response, which will overcome potential conflicting results from different biomarkers in the same assay. Broadly, this integrated nucleic acid biomarker signature may include at least the following four categories:

1) TME-related RNA biomarker genes, including key T cellinflamed signature genes, $\mathrm{T}$ cell dysfunction \& exclusion signature genes, and B cell signature genes.

2) Tumor multipotency and differentiation related RNA biomarker genes, such as MSP signature genes.

3) Tumor neoantigenicity-related DNA biomarker genes including frequently mutated core cancer genes for TMB, DNA mismatch repair genes, and MSI panel.

4) Other high impact genes, such as TGFB1 with a known role in promoting tumor immune escape and ICI resistance (107109), SOX10 with known function in promoting $\mathrm{T}$ cellmediated tumor cell attacking $(110,111)$, SERPINB9 with a demonstrated role in regulating ICI resistance, and POLE/ POLD1 with an established role in contributing to high TMB in some cancers (54). These high impact genes can come from both tumor cells and tumor infiltrating immune cells.

To ensure its clinical utility and economic feasibility, this integrated nucleic acid signature panel should be large enough to capture all key ICI responsive features and allow calculation of a reliable TMB, and small enough to be economically and technically feasible for broad application in daily clinical practice using next generation sequencing platforms. Because this integrated nucleic acid biomarker panel can comprehensively analyze DNA and RNA markers in one assay instead of two, it will have enhanced cost efficiency, reduced assay time, and require less biological material (total nucleic acids as input). This integrated assay includes multiple contributing factors to ICI response, and will likely be more predictive for immunologically cold tumors or advanced tumors.

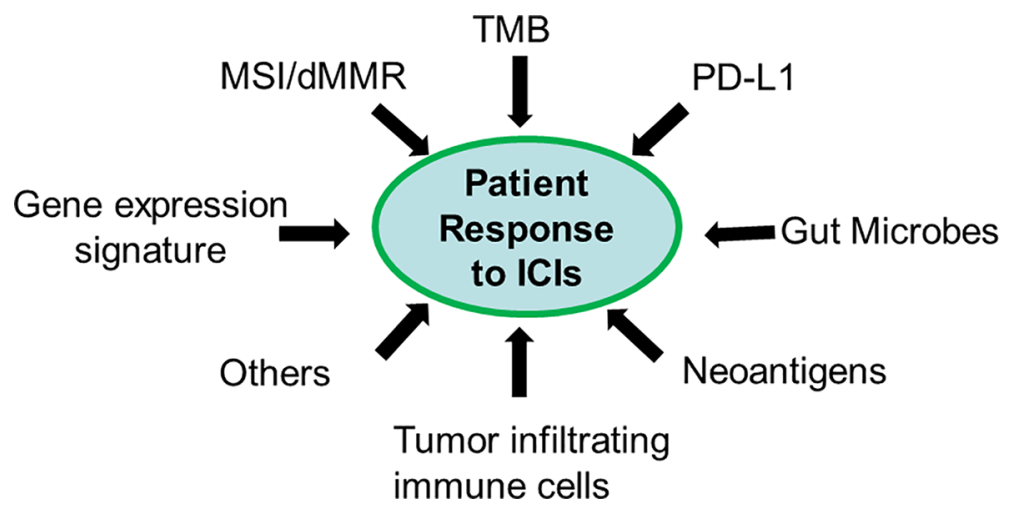

FIGURE 2 | Patient response to ICls is a quantitative trait. Each biomarker only captures a unique feature of the contributing factor (s). 


\section{AUTHOR CONTRIBUTIONS}

YW and XL conceived and designed the project. $\mathrm{AB}$ and $\mathrm{ZT}$ wrote the part of FDA approved predictive biomarkers. WHZ and XM wrote the part of Promising mutation biomarkers. QY and XZha wrote the part of Gene Signature Biomarkers. H-HC and XZha wrote the part of Emerging Combined Predictive Biomarkers. YW, H-HC and $\mathrm{XL}$ wrote the part of Future direction of predictive biomarker discovery. WZZ and MD edited the manuscript. All authors contributed to the article and approved the submitted version.

\section{REFERENCES}

1. Vaddepally RK, Kharel P, Pandey R, Garje R, Chandra AB. Review of Indications of FDA-Approved Immune Checkpoint Inhibitors Per NCCN Guidelines With the Level of Evidence. Cancers (Basel) (2020) 12(3):738-57. doi: 10.3390/cancers12030738

2. Davis AA, Patel VG. The Role of PD-L1 Expression as a Predictive Biomarker: An Analysis of All US Food and Drug Administration (FDA) Approvals of Immune Checkpoint Inhibitors. J Immunother Cancer (2019) 7(1):278. doi: 10.1186/s40425-019-0768-9

3. Gascon M, Isla D, Cruellas M, Galvez EM, Lastra R, Ocariz M, et al. Intratumoral Versus Circulating Lymphoid Cells as Predictive Biomarkers in Lung Cancer Patients Treated With Immune Checkpoint Inhibitors: Is the Easiest Path the Best One? Cells (2020) 9(6):1525-41. doi: 10.3390/cells9061525

4. Hennequart M, Pilotte L, Cane S, Hoffmann D, Stroobant V, Plaen E, et al. Constitutive IDO1 Expression in Human Tumors is Driven by Cyclooxygenase-2 and Mediates Intrinsic Immune Resistance. Cancer Immunol Res (2017) 5(8):695-709. doi: 10.1158/2326-6066.CIR-16-0400

5. Shin DS, Zaretsky JM, Escuin-Ordinas H, Garcia-Diaz A, Hu-Lieskovan S, Kalbasi A, et al. Primary Resistance to PD-1 Blockade Mediated by JAK1/2 Mutations. Cancer Discov (2017) 7(2):188-201. doi: 10.1158/2159-8290.CD-16-1223

6. Lim SY, Lee JH, Gide TN, Menzies AM, Guminski A, Carlino MS, et al. Circulating Cytokines Predict Immune-Related Toxicity in Melanoma Patients Receiving Anti-PD-1-Based Immunotherapy. Clin Cancer Res (2019) 25(5):1557-63. doi: 10.1158/1078-0432.CCR-18-2795

7. Rizzo A, Ricci AD, Brandi G. PD-L1, TMB, MSI, and Other Predictors of Response to Immune Checkpoint Inhibitors in Biliary Tract Cancer. Cancers (Basel) (2021) 13(3):558-71. doi: 10.3390/cancers13030558

8. Patel SP, Kurzrock R. PD-L1 Expression as a Predictive Biomarker in Cancer Immunotherapy. Mol Cancer Ther (2015) 14(4):847-56. doi: 10.1158/15357163.MCT-14-0983

9. Keenan TE, Burke KP, Van Allen EM. Genomic Correlates of Response to Immune Checkpoint Blockade. Nat Med (2019) 25(3):389-402. doi: 10.1038/s41591-019-0382-x

10. Mansfield AS, Aubry MC, Moser JC, Harrington SM, Dronca RS, Park SS, et al. Temporal and Spatial Discordance of Programmed Cell Death-Ligand 1 Expression and Lymphocyte Tumor Infiltration Between Paired Primary Lesions and Brain Metastases in Lung Cancer. Ann Oncol (2016) 27 (10):1953-8. doi: 10.1093/annonc/mdw289

11. Zhang J, Dang F, Ren J, Wei W. Biochemical Aspects of PD-L1 Regulation in Cancer Immunotherapy. Trends Biochem Sci (2018) 43(12):1014-32. doi: 10.1016/j.tibs.2018.09.004

12. Rizzo A, Mollica V, Massari F. Expression of Programmed Cell Death Ligand 1 as a Predictive Biomarker in Metastatic Urothelial Carcinoma Patients Treated With First-Line Immune Checkpoint Inhibitors Versus Chemotherapy: A Systematic Review and Meta-Analysis. Eur Urol Focus (2021) 00004-3(21):S2405-4569. doi: 10.1016/j.euf.2021.01.003

13. Montemagno C, Hagege A, Borchiellini D, Thamphya B, Rastoin O, Ambrosetti D, et al. Soluble Forms of PD-L1 and PD-1 as Prognostic and Predictive Markers of Sunitinib Efficacy in Patients With Metastatic Clear Cell Renal Cell Carcinoma. Oncoimmunology (2020) 9(1):1846901. doi: 10.1080/2162402X.2020.1846901

14. Hirsch FR, McElhinny A, Stanforth D, Ranger-Moore J, Jansson M, Kulangara K, et al. PD-L1 Immunohistochemistry Assays for Lung

\section{FUNDING}

This study was supported by the National Natural Science Foundation of China (No. 81670822, 81800805), and Qingdao Key Research Project (No. 19-6-1-3-nsh). AB contribution was supported by the Ministry of Science and Higher Education of the Russian Federation within the framework of state support for the creation and development of World-Class Research Centers "Digital biodesign and personalized healthcare" No 075-152020-926.

Cancer: Results From Phase 1 of the Blueprint PD-L1 IHC Assay Comparison Project. J Thorac Oncol (2017) 12(2):208-22. doi: 10.1016/ j.jtho.2016.11.2228

15. Marcus L, Lemery SJ, Keegan P, Pazdur R. FDA Approval Summary: Pembrolizumab for the Treatment of Microsatellite Instability-High Solid Tumors. Clin Cancer Res (2019) 25(13):3753-8. doi: 10.1158/1078 0432.CCR-18-4070

16. Le DT, Uram JN, Wang H, Bartlett BR, Kemberling H, Eyring AD, et al. PD1 Blockade in Tumors With Mismatch-Repair Deficiency. $N$ Engl J Med (2015) 372(26):2509-20. doi: 10.1056/NEJMoa1500596

17. Dudley JC, Lin MT, Le DT, Eshleman JR. Microsatellite Instability as a Biomarker for PD-1 Blockade. Clin Cancer Res (2016) 22(4):813-20. doi: 10.1158/1078-0432.CCR-15-1678

18. Giannakis M, Mu XJ, Shukla SA, Qian ZR, Cohen O, Nishihara R, et al. Genomic Correlates of Immune-Cell Infiltrates in Colorectal Carcinoma. Cell Rep (2016) 15(4):857-65. doi: 10.1016/j.celrep.2016.03.075

19. Ryan E, Sheahan K, Creavin B, Mohan HM, Winter DC. The Current Value of Determining the Mismatch Repair Status of Colorectal Cancer: A Rationale for Routine Testing. Crit Rev Oncol Hematol (2017) 116:38-57. doi: 10.1016/j.critrevonc.2017.05.006

20. Baretti M, Le DT. DNA Mismatch Repair in Cancer. Pharmacol Ther (2018) 189:45-62. doi: 10.1016/j.pharmthera.2018.04.004

21. Waalkes A, Smith N, Penewit K, Hempelmann J, Konnick EQ, Hause RJ, et al. Accurate Pan-Cancer Molecular Diagnosis of Microsatellite Instability by Single-Molecule Molecular Inversion Probe Capture and HighThroughput Sequencing. Clin Chem (2018) 64(6):950-8. doi: 10.1373/ clinchem.2017.285981

22. Engel KB, Moore HM. Effects of Preanalytical Variables on the Detection of Proteins by Immunohistochemistry in Formalin-Fixed, Paraffin-Embedded Tissue. Arch Pathol Lab Med (2011) 135(5):537-43. doi: 10.1043/2010-0702 RAIR.1

23. Shia J. Immunohistochemistry Versus Microsatellite Instability Testing for Screening Colorectal Cancer Patients at Risk for Hereditary Nonpolyposis Colorectal Cancer Syndrome. Part I. The Utility of Immunohistochemistry. J Mol Diagn (2008) 10(4):293-300. doi: 10.2353/jmoldx.2008.080031

24. Boland CR, Thibodeau SN, Hamilton SR, Sidransky D, Eshleman JR, Burt RW, et al. A National Cancer Institute Workshop on Microsatellite Instability for Cancer Detection and Familial Predisposition: Development of International Criteria for the Determination of Microsatellite Instability in Colorectal Cancer. Cancer Res (1998) 58(22):5248-57.

25. Suraweera N, Duval A, Reperant M, Vaury C, Furlan D, Leroy K, et al. Evaluation of Tumor Microsatellite Instability Using Five Quasimonomorphic Mononucleotide Repeats and Pentaplex PCR. Gastroenterology (2002) 123(6):1804-11. doi: 10.1053/gast.2002.37070

26. Berg KD, Glaser CL, Thompson RE, Hamilton SR, Griffin CA, Eshleman JR. Detection of Microsatellite Instability by Fluorescence Multiplex Polymerase Chain Reaction. J Mol Diagn (2000) 2(1):20-8. doi: 10.1016/S1525-1578(10) 60611-3

27. Duffy MJ, Crown J. Biomarkers for Predicting Response to Immunotherapy With Immune Checkpoint Inhibitors in Cancer Patients. Clin Chem (2019) 65(10):1228-38. doi: 10.1373/clinchem.2019.303644

28. Luchini C, Bibeau F, Ligtenberg MJL, Singh N, Nottegar A, Bosse T, et al ESMO Recommendations on Microsatellite Instability Testing for Immunotherapy in Cancer, and its Relationship With PD-1/PD-L1 
Expression and Tumour Mutational Burden: A Systematic Review-Based Approach. Ann Oncol (2019) 30(8):1232-43. doi: 10.1093/annonc/mdz116

29. Hause RJ, Pritchard CC, Shendure J, Salipante SJ. Classification and Characterization of Microsatellite Instability Across 18 Cancer Types. Nat Med (2016) 22(11):1342-50. doi: 10.1038/nm.4191

30. Johansen AFB, Kassentoft CG, Knudsen M, Laursen MB, Madsen AH, Iversen LH, et al. Validation of Computational Determination of Microsatellite Status Using Whole Exome Sequencing Data From Colorectal Cancer Patients. BMC Cancer (2019) 19(1):971. doi: 10.1186/ s12885-019-6227-7

31. Ashktorab H, Ahuja S, Kannan L, Llor X, Ellis NA, Xicola RM, et al. A MetaAnalysis of MSI Frequency and Race in Colorectal Cancer. Oncotarget (2016) 7(23):34546-57. doi: 10.18632/oncotarget.8945

32. Casey L, Singh N. POLE, MMR, and MSI Testing in Endometrial Cancer: Proceedings of the Isgyp Companion Society Session at the USCAP 2020 Annual Meeting. Int J Gynecol Pathol (2021) 40(1):5-16. doi: 10.1097/ PGP.0000000000000710

33. Yang Y, Shi Z, Bai R, Hu W. Heterogeneity of MSI-H Gastric Cancer Identifies a Subtype With Worse Survival. J Med Genet (2021) 58(1):12-9. doi: 10.1136/jmedgenet-2019-106609

34. Murphy MA, Wentzensen N. Frequency of Mismatch Repair Deficiency in Ovarian Cancer: A Systematic Review This Article is a US Government Work and, as Such, is in the Public Domain of the United States of America. Int J Cancer (2011) 129(8):1914-22. doi: 10.1002/ijc.25835

35. Lee PJ, McNulty S, Duncavage EJ, Heusel JW, Hagemann IS. Clinical Targeted Next-Generation Sequencing Shows Increased Mutational Load in Endometrioid-Type Endometrial Adenocarcinoma With Deficient DNA Mismatch Repair. Int J Gynecol Pathol (2018) 37(6):581-9. doi: 10.1097/ PGP.0000000000000459

36. Bao F, Panarelli NC, Rennert H, Sherr DL, Yantiss RK. Neoadjuvant Therapy Induces Loss of MSH6 Expression in Colorectal Carcinoma. Am J Surg Pathol (2010) 34(12):1798-804. doi: 10.1097/PAS.0b013e3181f906cc

37. Goldstein JB, Wu W, Borras E, Masand G, Cuddy A, Mork ME, et al. Can Microsatellite Status of Colorectal Cancer be Reliably Assessed After Neoadjuvant Therapy? Clin Cancer Res (2017) 23(17):5246-54. doi: 10.1158/1078-0432.CCR-16-2994

38. Le DT, Durham JN, Smith KN, Wang H, Bartlett BR, Aulakh LK, et al. Mismatch Repair Deficiency Predicts Response of Solid Tumors to PD-1 Blockade. Science (2017) 357(6349):409-13. doi: 10.1126/science.aan6733

39. Alexandrov LB, Nik-Zainal S, Wedge DC, Aparicio SA, Behjati S, Biankin $\mathrm{AV}$, et al. Signatures of Mutational Processes in Human Cancer. Nature (2013) 500(7463):415-21. doi: 10.1038/nature12477

40. Klempner SJ, Fabrizio D, Bane S, Reinhart M, Peoples T, Ali SM, et al. Tumor Mutational Burden as a Predictive Biomarker for Response to Immune Checkpoint Inhibitors: A Review of Current Evidence. Oncologist (2020) 25(1):e147-59. doi: 10.1634/theoncologist.2019-0244

41. Teo MY, Seier K, Ostrovnaya I, Regazzi AM, Kania BE, Moran MM, et al. Alterations in DNA Damage Response and Repair Genes as Potential Marker of Clinical Benefit From PD-1/PD-L1 Blockade in Advanced Urothelial Cancers. J Clin Oncol (2018) 36(17):1685-94. doi: 10.1200/ JCO.2017.75.7740

42. Song Y, Huang J, Liang D, Hu Y, Mao B, Li Q, et al. DNA Damage Repair Gene Mutations are Indicative of a Favorable Prognosis in Colorectal Cancer Treated With Immune Checkpoint Inhibitors. Front Oncol (2020) 10:549777. doi: 10.3389/fonc.2020.549777

43. Joshi M, Grivas P, Mortazavi A, Monk P, Clinton SK, Sue-Ann Woo M, et al. Alterations of DNA Damage Response Genes Correlate With Response and Overall Survival in Anti-PD-1/PD-L1-Treated Advanced Urothelial Cancer. Cancer Med (2020) 9(24):9365-72. doi: 10.1002/cam4.3552

44. Pan YR, Wu CE, Wang YC, Yeh YC, Lu ML, Hung YP, et al. Establishment of a Novel Gene Panel as a Biomarker of Immune Checkpoint Inhibitor Response. Clin Transl Immunol (2020) 9(7):e1145. doi: 10.1002/cti2.1145

45. Jiang M, Jia K, Wang L, Li W, Chen B, Liu Y, et al. Alterations of DNA Damage Response Pathway: Biomarker and Therapeutic Strategy for Cancer Immunotherapy. Acta Pharm Sin B (2021). doi: 10.1016/j.apsb.2021.01.003

46. Snyder A, Makarov V, Merghoub T, Yuan J, Zaretsky JM, Desrichard A, et al. Genetic Basis for Clinical Response to CTLA-4 Blockade in Melanoma. N Engl J Med (2014) 371(23):2189-99. doi: 10.1056/NEJMoa1406498
47. Rizvi NA, Hellmann MD, Snyder A, Kvistborg P, Makarov V, Havel JJ, et al. Cancer Immunology. Mutational Landscape Determines Sensitivity to PD-1 Blockade in non-Small Cell Lung Cancer. Science (2015) 348(6230):124-8. doi: $10.1126 /$ science.aaa1348

48. Riaz N, Havel JJ, Makarov V, Desrichard A, Urba WJ, Sims JS, et al. Tumor and Microenvironment Evolution During Immunotherapy With Nivolumab. Cell (2017) 171(4):934-49.e16. doi: 10.1016/j.cell.2017.09.028

49. Eroglu Z, Zaretsky JM, Hu-Lieskovan S, Kim DW, Algazi A, Johnson DB, et al. High Response Rate to PD-1 Blockade in Desmoplastic Melanomas. Nature (2018) 553(7688):347-50. doi: 10.1038/nature25187

50. Goodman AM, Kato S, Bazhenova L, Patel SP, Frampton GM, Miller V, et al. Tumor Mutational Burden as an Independent Predictor of Response to Immunotherapy in Diverse Cancers. Mol Cancer Ther (2017) 16(11):2598608. doi: 10.1158/1535-7163.MCT-17-0386

51. Rizvi H, Sanchez-Vega F, La K, Chatila W, Jonsson P, Halpenny D, et al. Molecular Determinants of Response to Anti-Programmed Cell Death (PD)-1 and Anti-Programmed Death-Ligand 1 (PD-L1) Blockade in Patients With nonSmall-Cell Lung Cancer Profiled With Targeted Next-Generation Sequencing. J Clin Oncol (2018) 36(7):633-41. doi: 10.1200/JCO.2017.75.3384

52. Carbone DP, Reck M, Paz-Ares L, Creelan B, Horn L, Steins M, et al. FirstLine Nivolumab in Stage IV or Recurrent non-Small-Cell Lung Cancer. N Engl J Med (2017) 376(25):2415-26. doi: 10.1056/NEJMoa1613493

53. Buchhalter I, Rempel E, Endris V, Allgauer M, Neumann O, Volckmar AL, et al. Size Matters: Dissecting Key Parameters for Panel-Based Tumor Mutational Burden Analysis. Int J Cancer (2019) 144(4):848-58. doi: $10.1002 / \mathrm{ijc} .31878$

54. Chalmers ZR, Connelly CF, Fabrizio D, Gay L, Ali SM, Ennis R, et al. Analysis of 100,000 Human Cancer Genomes Reveals the Landscape of Tumor Mutational Burden. Genome Med (2017) 9(1):34. doi: 10.1186/ s13073-017-0424-2

55. Stenzinger A, Allen JD, Maas J, Stewart MD, Merino DM, Wempe MM, et al Tumor Mutational Burden Standardization Initiatives: Recommendations for Consistent Tumor Mutational Burden Assessment in Clinical Samples to Guide Immunotherapy Treatment Decisions. Genes Chromosomes Cancer (2019) 58(8):578-88. doi: 10.1002/gcc.22733

56. Merino DM, McShane LM, Fabrizio D, Funari V, Chen SJ, White JR, et al Establishing Guidelines to Harmonize Tumor Mutational Burden (TMB): in Silico Assessment of Variation in TMB Quantification Across Diagnostic Platforms: Phase I of the Friends of Cancer Research TMB Harmonization Project. J Immunother Cancer (2020) 8(1):e000147-161. doi: 10.1136/jitc2019-000147

57. Stenzinger A, Endris V, Budczies J, Merkelbach-Bruse S, Kazdal D, Dietmaier W, et al. Harmonization and Standardization of Panel-Based Tumor Mutational Burden Measurement: Real-World Results and Recommendations of the Quality in Pathology Study. J Thorac Oncol (2020) 15(7):1177-89. doi: 10.1016/j.jtho.2020.01.023

58. Yarchoan M, Hopkins A, Jaffee EM. Tumor Mutational Burden and Response Rate to PD-1 Inhibition. N Engl J Med (2017) 377(25):2500-1. doi: 10.1056/NEJMc1713444

59. Fumet JD, Truntzer C, Yarchoan M, Ghiringhelli F. Tumour Mutational Burden as a Biomarker for Immunotherapy: Current Data and Emerging Concepts. Eur J Cancer (2020) 131:40-50. doi: 10.1016/j.ejca.2020.02.038

60. Campbell BB, Light N, Fabrizio D, Zatzman M, Fuligni F, de Borja R, et al. Comprehensive Analysis of Hypermutation in Human Cancer. Cell (2017) 171(5):1042-56.e10. doi: 10.1016/j.cell.2017.09.048

61. Chae YK, Anker JF, Bais P, Namburi S, Giles FJ, Chuang JH. Mutations in DNA Repair Genes are Associated With Increased Neo-Antigen Load and Activated T Cell Infiltration in Lung Adenocarcinoma. Oncotarget (2018) 9 (8):7949-60. doi: 10.18632/oncotarget.23742

62. Voutsadakis IA. Polymerase Epsilon Mutations and Concomitant Beta2Microglobulin Mutations in Cancer. Gene (2018) 647:31-8. doi: 10.1016/ j.gene.2018.01.030

63. Turajlic S, Litchfield K, Xu H, Rosenthal R, McGranahan N, Reading JL, et al. Insertion-and-Deletion-Derived Tumour-Specific Neoantigens and the Immunogenic Phenotype: A Pan-Cancer Analysis. Lancet Oncol (2017) 18 (8):1009-21. doi: 10.1016/S1470-2045(17)30516-8

64. McGranahan N, Furness AJ, Rosenthal R, Ramskov S, Lyngaa R, Saini SK, et al. Clonal Neoantigens Elicit T Cell Immunoreactivity and Sensitivity to 
Immune Checkpoint Blockade. Science (2016) 351(6280):1463-9. doi: 10.1126/science.aaf1490

65. Wu Y, Xu J, Xu J, Wang Y, Wang L, Lv W, et al. The Predictive Value of Tumor Mutation Burden for Immune Checkpoint Inhibitors Therapy in non-Small Cell Lung Cancer is Affected by Patients' Age. Biomark Res (2020) 8:9. doi: 10.1186/s40364-020-00188-2

66. Samstein RM, Lee CH, Shoushtari AN, Hellmann MD, Shen R, Janjigian YY, et al. Tumor Mutational Load Predicts Survival After Immunotherapy Across Multiple Cancer Types. Nat Genet (2019) 51(2):202-6. doi: 10.1038/s41588-018-0312-8

67. Balar AV, Galsky MD, Rosenberg JE, Powles T, Petrylak DP, Bellmunt J, et al. Atezolizumab as First-Line Treatment in Cisplatin-Ineligible Patients With Locally Advanced and Metastatic Urothelial Carcinoma: A SingleArm, Multicentre, Phase 2 Trial. Lancet (2017) 389(10064):67-76. doi: 10.1016/S0140-6736(16)32455-2

68. Mouw KW, Goldberg MS, Konstantinopoulos PA, D’Andrea AD. DNA Damage and Repair Biomarkers of Immunotherapy Response. Cancer Discov (2017) 7(7):675-93. doi: 10.1158/2159-8290.CD-17-0226

69. Li J, Yen C, Liaw D, Podsypanina K, Bose S, Wang SI, et al. PTEN, a Putative Protein Tyrosine Phosphatase Gene Mutated in Human Brain, Breast, and Prostate Cancer. Science (1997) 275(5308):1943-7. doi: 10.1126/ science.275.5308.1943

70. Sansal I, Sellers WR. The Biology and Clinical Relevance of the PTEN Tumor Suppressor Pathway. J Clin Oncol (2004) 22(14):2954-63. doi: 10.1200/JCO.2004.02.141

71. Shen WH, Balajee AS, Wang J, Wu H, Eng C, Pandolfi PP, et al. Essential Role for Nuclear PTEN in Maintaining Chromosomal Integrity. Cell (2007) 128(1):157-70. doi: 10.1016/j.cell.2006.11.042

72. Alimonti A, Carracedo A, Clohessy JG, Trotman LC, Nardella C, Egia A, et al. Subtle Variations in Pten Dose Determine Cancer Susceptibility. Nat Genet (2010) 42(5):454-8. doi: 10.1038/ng.556

73. Peng W, Chen JQ, Liu C, Malu S, Creasy C, Tetzlaff MT, et al. Loss of PTEN Promotes Resistance to T Cell-Mediated Immunotherapy. Cancer Discovery (2016) 6(2):202-16. doi: 10.1158/2159-8290.CD-15-0283

74. Chen H, Chong W, Teng C, Yao Y, Wang X, Li X. The Immune ResponseRelated Mutational Signatures and Driver Genes in non-Small-Cell Lung Cancer. Cancer Sci (2019) 110(8):2348-56. doi: 10.1111/cas.14113

75. Szpirer J, Pedeutour F, Kesti T, Riviere M, Syvaoja JE, Turc-Carel C, et al. Localization of the Gene for DNA Polymerase Epsilon (POLE) to Human Chromosome 12q24.3 and Rat Chromosome 12 by Somatic Cell Hybrid Panels and Fluorescence in Situ Hybridization. Genomics (1994) 20(2):2236. doi: 10.1006/geno.1994.1156

76. Rayner E, van Gool IC, Palles C, Kearsey SE, Bosse T, Tomlinson I, et al. A Panoply of Errors: Polymerase Proofreading Domain Mutations in Cancer. Nat Rev Cancer (2016) 16(2):71-81. doi: 10.1038/nrc.2015.12

77. Song Z, Cheng G, Xu C, Wang W, Shao Y, Zhang Y. Clinicopathological Characteristics of POLE Mutation in Patients With non-Small-Cell Lung Cancer. Lung Cancer (2018) 118:57-61. doi: 10.1016/j.lungcan.2018.02.004

78. Agbor AA, Goksenin AY, LeCompte KG, Hans SH, Pursell ZF. Human Pol Epsilon-Dependent Replication Errors and the Influence of Mismatch Repair on Their Correction. DNA Repair (Amst) (2013) 12(11):954-63. doi: 10.1016/j.dnarep.2013.08.012

79. Wang F, Zhao Q, Wang YN, Jin Y, He MM, Liu ZX, et al. Evaluation of POLE and POLD1 Mutations as Biomarkers for Immunotherapy Outcomes Across Multiple Cancer Types. JAMA Oncol (2019) 5(10):1504-6. doi: 10.1001/jamaoncol.2019.2963

80. Aviel-Ronen S, Blackhall FH, Shepherd FA, Tsao MS. K-Ras Mutations in non-Small-Cell Lung Carcinoma: A Review. Clin Lung Cancer (2006) 8 (1):30-8. doi: 10.3816/CLC.2006.n.030

81. Guan JL, Zhong WZ, An SJ, Yang JJ, Su J, Chen ZH, et al. KRAS Mutation in Patients With Lung Cancer: A Predictor for Poor Prognosis But Not for EGFR-Tkis or Chemotherapy. Ann Surg Oncol (2013) 20(4):1381-8. doi: 10.1245/s10434-012-2754-Z

82. Legras A, Barritault M, Tallet A, Fabre E, Guyard A, Rance B, et al. Validity of Targeted Next-Generation Sequencing in Routine Care for Identifying Clinically Relevant Molecular Profiles in non-Small-Cell Lung Cancer: Results of a 2-Year Experience on 1343 Samples. J Mol Diagn (2018) 20 (4):550-64. doi: 10.1016/j.jmoldx.2018.04.002
83. Schabath MB, Welsh EA, Fulp WJ, Chen L, Teer JK, Thompson ZJ, et al. Differential Association of STK11 and TP53 With KRAS Mutation-Associated Gene Expression, Proliferation and Immune Surveillance in Lung Adenocarcinoma. Oncogene (2016) 35(24):3209-16. doi: 10.1038/onc.2015.375

84. Shackelford DB, Shaw RJ. The LKB1-AMPK Pathway: Metabolism and Growth Control in Tumour Suppression. Nat Rev Cancer (2009) 9(8):56375. doi: $10.1038 / \mathrm{nrc} 2676$

85. Gill RK, Yang SH, Meerzaman D, Mechanic LE, Bowman ED, Jeon HS, et al. Frequent Homozygous Deletion of the LKB1/STK11 Gene in non-Small Cell Lung Cancer. Oncogene (2011) 30(35):3784-91. doi: 10.1038/onc.2011.98

86. La Fleur L, Falk-Sorqvist E, Smeds P, Berglund A, Sundstrom M, Mattsson JS, et al. Mutation Patterns in a Population-Based non-Small Cell Lung Cancer Cohort and Prognostic Impact of Concomitant Mutations in KRAS and TP53 or STK11. Lung Cancer (2019) 130:50-8. doi: 10.1016/ j.lungcan.2019.01.003

87. Skoulidis F, Heymach JV. Co-Occurring Genomic Alterations in non-SmallCell Lung Cancer Biology and Therapy. Nat Rev Cancer (2019) 19(9):495509. doi: 10.1038/s41568-019-0179-8

88. Passiglia F, Cappuzzo F, Alabiso O, Bettini AC, Bidoli P, Chiari R, et al. Efficacy of Nivolumab in Pre-Treated non-Small-Cell Lung Cancer Patients Harbouring KRAS Mutations. Br J Cancer (2019) 120(1):57-62. doi: 10.1038/s41416-018-0234-3

89. Hellmann MD, Nathanson T, Rizvi H, Creelan BC, Sanchez-Vega F, Ahuja A, et al. Genomic Features of Response to Combination Immunotherapy in Patients With Advanced non-Small-Cell Lung Cancer. Cancer Cell (2018) 33 (5):843-52.e4. doi: 10.1016/j.ccell.2018.03.018

90. Skoulidis F, Goldberg ME, Greenawalt DM, Hellmann MD, Awad MM, Gainor JF, et al. STK11/LKB1 Mutations and PD-1 Inhibitor Resistance in KRAS-Mutant Lung Adenocarcinoma. Cancer Discov (2018) 8(7):822-35. doi: 10.1158/2159-8290.CD-18-0099

91. Bange E, Marmarelis ME, Hwang WT, Yang YX, Thompson JC, Rosenbaum J, et al. Impact of KRAS and TP53 Co-Mutations on Outcomes After FirstLine Systemic Therapy Among Patients With STK11-Mutated Advanced non-Small-Cell Lung Cancer. JCO Precis Oncol (2019) 3:PO.18.00326. doi: 10.1200/PO.18.00326

92. Koyama S, Akbay EA, Li YY, Aref AR, Skoulidis F, Herter-Sprie GS, et al. STK11/LKB1 Deficiency Promotes Neutrophil Recruitment and Proinflammatory Cytokine Production to Suppress T-Cell Activity in the Lung Tumor Microenvironment. Cancer Res (2016) 76(5):999-1008. doi: 10.1158/0008-5472.CAN-15-1439

93. Ayers M, Lunceford J, Nebozhyn M, Murphy E, Loboda A, Kaufman DR, et al. IFN-Gamma-Related Mrna Profile Predicts Clinical Response to PD-1 Blockade. J Clin Invest (2017) 127(8):2930-40. doi: 10.1172/JC191190

94. Gajewski TF, Schreiber H, Fu YX. Innate and Adaptive Immune Cells in the Tumor Microenvironment. Nat Immunol (2013) 14(10):1014-22. doi: 10.1038/ni.2703

95. Joyce JA, Fearon DT. T Cell Exclusion, Immune Privilege, and the Tumor Microenvironment. Science (2015) 348(6230):74-80. doi: 10.1126/ science.aaa6204

96. Jiang P, Gu S, Pan D, Fu J, Sahu A, Hu X, et al. Signatures of T Cell Dysfunction and Exclusion Predict Cancer Immunotherapy Response. Nat Med (2018) 24(10):1550-8. doi: 10.1038/s41591-018-0136-1

97. Perez-Guijarro E, Yang HH, Araya RE, El Meskini R, Michael HT, Vodnala SK, et al. Multimodel Preclinical Platform Predicts Clinical Response of Melanoma to Immunotherapy. Nat Med (2020) 26(5):781-91. doi: 10.1038/ s41591-020-0818-3

98. Cabrita R, Lauss M, Sanna A, Donia M, Skaarup Larsen M, Mitra S, et al. Tertiary Lymphoid Structures Improve Immunotherapy and Survival in Melanoma. Nature (2020) 577(7791):561-5. doi: 10.1038/s41586-019-1914-8

99. Helmink BA, Reddy SM, Gao J, Zhang S, Basar R, Thakur R, et al. B Cells and Tertiary Lymphoid Structures Promote Immunotherapy Response. Nature (2020) 577(7791):549-55. doi: 10.1038/s41586-019-1922-8

100. He M, Abro B, Kaushal M, Chen L, Chen T, Gondim M, et al. Tumor Mutation Burden and Checkpoint Immunotherapy Markers in Primary and Metastatic Synovial Sarcoma. Hum Pathol (2020) 100:15-23. doi: 10.1016/ j.humpath.2020.04.007

101. Becht E, Giraldo NA, Lacroix L, Buttard B, Elarouci N, Petitprez F, et al. Estimating the Population Abundance of Tissue-Infiltrating Immune and 
Stromal Cell Populations Using Gene Expression. Genome Biol (2016) 17 (1):218. doi: 10.1186/s13059-016-1070-5

102. Buzdin A, Sorokin M, Garazha A, Sekacheva M, Kim E, Zhukov N, et al. Molecular Pathway Activation - New Type of Biomarkers for Tumor Morphology and Personalized Selection of Target Drugs. Semin Cancer Biol (2018) 53:110-24. doi: 10.1016/j.semcancer.2018.06.003

103. Borisov N, Sorokin M, Garazha A, Buzdin A. Quantitation of Molecular Pathway Activation Using RNA Sequencing Data. Methods Mol Biol (2020) 2063:189-206. doi: 10.1007/978-1-0716-0138-9_15

104. Buzdin A, Sorokin M, Garazha A, Glusker A, Aleshin A, Poddubskaya E, et al. RNA Sequencing for Research and Diagnostics in Clinical Oncology. Semin Cancer Biol (2020) 60:311-23. doi: 10.1016/j.semcancer.2019.07.010

105. Moisseev A, Albert E, Lubarsky D, Schroeder D, Clark J. Transcriptomic and Genomic Testing to Guide Individualized Treatment in Chemoresistant Gastric Cancer Case. Biomedicines (2020) 8(3):67-77. doi: 10.3390/ biomedicines 8030067

106. Cristescu R, Mogg R, Ayers M, Albright A, Murphy E, Yearley J, et al. Pan-Tumor Genomic Biomarkers for PD-1 Checkpoint Blockade-Based Immunotherapy. Science (2018) 362(6411):eaar3593. doi: 10.1126/science.aar3593

107. Sharma P, Hu-Lieskovan S, Wargo JA, Ribas A. Primary, Adaptive, and Acquired Resistance to Cancer Immunotherapy. Cell (2017) 168(4):707-23. doi: 10.1016/j.cell.2017.01.017

108. Tauriello DVF, Palomo-Ponce S, Stork D, Berenguer-Llergo A, BadiaRamentol J, Iglesias $\mathrm{M}$, et al. Tgfbeta Drives Immune Evasion in
Genetically Reconstituted Colon Cancer Metastasis. Nature (2018) 554 (7693):538-43. doi: 10.1038/nature25492

109. Mariathasan S, Turley SJ, Nickles D, Castiglioni A, Yuen K, Wang Y, et al. Powles: Tgfbeta Attenuates Tumour Response to PD-L1 Blockade by Contributing to Exclusion of T Cells. Nature (2018) 554(7693):544-8. doi: 10.1038/nature25501

110. Patel SJ, Sanjana NE, Kishton RJ, Eidizadeh A, Vodnala SK, Cam M, et al. Identification of Essential Genes for Cancer Immunotherapy. Nature (2017) 548(7669):537-42. doi: 10.1038/nature23477

111. Khong HT, Rosenberg SA. The Waardenburg Syndrome Type 4 Gene, SOX10, is a Novel Tumor-Associated Antigen Identified in a Patient With a Dramatic Response to Immunotherapy. Cancer Res (2002) 62(11):3020-3.

Conflict of Interest: The authors declare that the research was conducted in the absence of any commercial or financial relationships that could be construed as a potential conflict of interest.

Copyright (C) 2021 Wang, Tong, Zhang, Zhang, Buzdin, Mu, Yan, Zhao, Chang, Duhon, Zhou, Zhao, Chen and Li. This is an open-access article distributed under the terms of the Creative Commons Attribution License (CC BY). The use, distribution or reproduction in other forums is permitted, provided the original author(s) and the copyright owner(s) are credited and that the original publication in this journal is cited, in accordance with accepted academic practice. No use, distribution or reproduction is permitted which does not comply with these terms. 